\title{
The Effectiveness Study of Individualized Nursing Intervention on Postoperative Rehabilitation of Patients with Gynecological Tumor
}

\author{
Ruifang Chen*, Yifen Chen and Xueying Feng \\ The People's Hospital of Yangjiang City, Yangjiang, Guangdong 529500, China
}

\begin{abstract}
Objective: to study the effect of individualized nursing intervention on postoperative rehabilitation of patients with gynecological tumor. Methods: 80 cases of patients with gynecological tumor were randomly divided into two groups. The comparative group: 40 cases received the traditional nursing which was according to the conventional gynecologic operation; the observation group: 40 cases received the special and sustainable individualized nursing intervention which was according to the patients' needs and characteristics in every stage. To compare the life quality, the treatment compliance, and the recurrence rate in 6 and 12 months after operation of patients in these two groups. Results: The life quality of patients in the observation group was obviously better than that in the comparative group, $p<0.05$. The treatment compliance of patients in the observation group was obviously higher than that in the comparative group, $p<0.01$. The recurrence rate in 6 and 12 months of patients after operation in the observation group was obviously lower than that in the comparative group, $p<0.05$. Conclusion: Individualized nursing intervention given to patients with gynecological tumor after operation obviously changes all kinds of passive psychology and bad behavior of patients to the disease, life and outlook on life. Patients can be aroused individual potential, form their own active treatment belief, and lighten the psychological pressure. The individualized nursing intervention helps patients improve their life quality and the treatment compliance, but effectively reduce the recurrence rate after operation. It not only improves patients' long term effect and prognosis, but also plays an important role in patients' rehabilitation.
\end{abstract}

\section{KEYWORDS}

Gynecological tumor

Individualized nursing

Long-term effect

\section{Introduction}

The surgical treatment is the main method to cure gynecological tumor, and uterus, ovary, and oviduct are the reproductive organs peculiar to female. The operation changes the structure of reproductive organs more or less and the sexual function and it also makes the body uncomfortable. The operation often has negative influence on patients'

Copyright (c) 2015 Ruifang Chen et al.

doi: $10.18686 /$ jn.v4i2.5

Received: March 2, 2015; Accepted: May 8, 2015; Published online: June 28,2015

This is an open-access article distributed under the terms of the Creative Commons Attribution Unported License (http://creativecommons.org/ licenses/by-nc/4.0/), which permits unrestricted use, distribution, and reproduction in any medium, provided the original work is properly cited.

${ }^{\star}$ Corresponding author: The People's Hospital of Yangjiang City, Yangjiang, Guangdong 529500, China. E-mail: chenrf1919@sina.com psychology, physiology and life. In order to lighten the psychological pressure, promote the rehabilitation after operation, improve the life quality and increase the treatment effect, according to the working practice in the gynecologic department, the author gave individualized nursing intervention to patients, which made satisfactory results in clinic [1].

\section{Clinical data}

80 cases of patients with gynecological tumor from April 2013 to April 2015 in our hospital were selected. All patients were first admission and with benign tumor or selective operation of malignant tumor I Stage. They also had no disturbance of consciousness or mental diseases. They were all married and graduated from the junior middle school or higher. Their ages were from 43 to 68 , female. Causes: 46 cases with hysteromyoma, 24 cases with ovar- 
ian neoplasms and 10 cases with cervical cancer. All cases were divided into 40 cases in the observation group and 40 cases in the comparative group. Differences between the two groups in age, education level, marital status, disease species, operative method and nutritional condition were not significant.

\section{Methods}

\subsection{Comparative group}

This group will receive the traditional nursing which was according to the conventional gynecologic operation by the doctor's suggestions.

\subsection{Observation group}

This group is received the individualized nursing intervention which was according to the patients' needs divided into three steps. Full-time nurses were in charge.

\subsubsection{First step}

This step refers to nursing before operation. Pay more attention to reduce patients' stress, fear and anxiety and make sure they have a good mental state to take operation. First, we made evaluation of patients after admission and mastered the situations and needs under different characteristics and bad psychology. According to patients' different characteristics, full-time nurses implemented individualized nursing in the whole course. In all the evaluation, we found all patients always had stress and anxiety on operation because of their fear. We picked them up in different ways according to different characteristics. 0.5-1 hour once a day till the day before operation day. We also introduced the hospitalization environment, onset characteristics and surgical problems, etc in detail to help them solve the urgent problems, which made patients feel like at home, reduced or released stress and anxiety before operation and had a good mental state to take operation [2].

\subsubsection{Second step}

This step refers to the intervention after operation. In this step, it is important to improve the fit capability between patients and the treatment and reduce postoperative complications. In this step, we communicated with patients every day, guided their diets, drugs and daily life after operation, asked them to take functional exercise and introduced all kinds of nursing keys and problems of the drainage tube in detail. We also observed diseases and made patients relaxed. Listening to gentle music was an effective way to relax body and mind.

\subsubsection{Third step}

This step is based on the hospital discharge guide and follow-up to increase patients' nursing skills by themselves and improve their prognosis. We made family nursing plans according to patients' rehabilitation condition. Return visit to hospital every three months, and prognosis for one year after discharge.

To obverse the life quality in these two groups on admission and after discharge, the treatment compliance of patients after discharge in three months and six months, and the recurrence rate after six months and twelve months after operation. Then compare the results.

\section{Observation and evaluation criteria 4.1. Life quality}

Evaluate by the life quality score (provisional draft) of patients with tumor made in 1990. Choose eight contents related to pain and psychological factor: diets, spirits, sleep, family understanding and cooperation, understanding of cancer, attitude to the treatment, daily life and facial expression. Use 1-5 grade to score, the worst score is 1 point and the best score is 5 points. The more points one gets, the better quality of life one will have.

\subsection{Treatment compliance}

Make the compliance survey by oneself, which includes taking drugs on time, functional exercise, regular reexamination, regular inspection and diagnosis in time.

\section{Results}

Before taking individualized nursing intervention, patients in two groups had adverse cognition and behavior on life quality in different levels. But different project evaluations were not significant in Statistic. Life quality comparison between two groups after taking individualized nursing intervention, see Table 1 .

Table 1. Life quality comparison between two groups after taking individualized nursing intervention.

\begin{tabular}{cccccccc}
\hline Group & $\mathrm{n}$ & $\begin{array}{c}1-2 \\
\text { points }\end{array}$ & $\begin{array}{c}3-4 \\
\text { points }\end{array}$ & $\begin{array}{c}5 \\
\text { points }\end{array}$ & $x^{2}$ & $p$ \\
\hline Observation Group & 40 & 6 & 6 & 28 & 3.12 & $<0.05$ \\
Comparative Group & 40 & 12 & 17 & 11 & - & - \\
\hline
\end{tabular}

Table 1 showed after taking individualized nursing intervention, the life quality of patients in the observation group was obviously better than that in the comparative group, $p<0.05$.

\subsection{Treatment compliance comparison}

Table 2 showed the treatment compliance of patients in the observation group was obviously higher than that in the comparative group in three months after discharge, $p<$ 0.01 .

Table 3 showed the treatment compliance of patients in the observation group was obviously higher than that in the comparative group in twelve months after discharge, $p$ $<0.01$.

\subsection{Recurrence rate comparison}

Recurrence rate comparison between two group after 6 
Table 2. Treatment compliance comparison in three months after discharge.

\begin{tabular}{|c|c|c|c|c|c|c|}
\hline Group & $\mathrm{n}$ & $\begin{array}{c}\text { Taking Drugs on } \\
\text { Time }\end{array}$ & $\begin{array}{l}\text { Functional } \\
\text { Exercise }\end{array}$ & $\begin{array}{c}\text { Regular } \\
\text { Reexamination }\end{array}$ & $\begin{array}{l}\text { Regular } \\
\text { Inspection }\end{array}$ & $\begin{array}{c}\text { Diagnosis } \\
\text { in Time }\end{array}$ \\
\hline Observation Group & 40 & 38 & 36 & 38 & 39 & 38 \\
\hline Comparative Group & 40 & 28 & 24 & 28 & 21 & 18 \\
\hline$x^{2}$ & - & 8.658 & 9.600 & 8.658 & 21.600 & 23.809 \\
\hline$p$ & - & $<0.01$ & $<0.01$ & $<0.01$ & $<0.01$ & $<0.01$ \\
\hline
\end{tabular}

Table 3. Treatment compliance comparison in six months after discharge.

\begin{tabular}{|c|c|c|c|c|c|c|}
\hline Group & $\mathrm{n}$ & $\begin{array}{c}\text { Taking Drugs on } \\
\text { Time }\end{array}$ & $\begin{array}{c}\text { Functional } \\
\text { Exercise }\end{array}$ & $\begin{array}{c}\text { Regular } \\
\text { Reexamination }\end{array}$ & $\begin{array}{l}\text { Regular } \\
\text { Inspection }\end{array}$ & $\begin{array}{l}\text { Diagnosis } \\
\text { in Time }\end{array}$ \\
\hline Observation Group & 40 & 35 & 39 & 38 & 34 & 36 \\
\hline Comparative Group & 40 & 22 & 21 & 18 & 20 & 24 \\
\hline$x^{2}$ & - & 10.313 & 21.600 & 23.809 & 11.168 & 9.600 \\
\hline$p$ & - & $<0.01$ & $<0.01$ & $<0.01$ & $<0.01$ & $<0.01$ \\
\hline
\end{tabular}

Table 4. Recurrence rate comparison between two groups.

\begin{tabular}{|c|c|c|c|c|c|}
\hline \multirow{2}{*}{ Group } & \multirow{2}{*}{$\mathrm{n}$} & \multicolumn{2}{|c|}{ In 6 months after operation } & \multicolumn{2}{|c|}{ In 12 months after operation } \\
\hline & & Normal & Recurrence & Normal & Recurrence \\
\hline Observation Group & 40 & 39 & 1 & 38 & 2 \\
\hline Comparative Group & 40 & 34 & 6 & 28 & 12 \\
\hline$x^{2}$ & - & \multicolumn{2}{|c|}{4.3502} & \multicolumn{2}{|c|}{8066} \\
\hline$p$ & - & \multicolumn{2}{|c|}{$<0.05$} & \multicolumn{2}{|c|}{$<0.05$} \\
\hline
\end{tabular}

months and 12 months. See Table 4.

Table 4 showed to compare the recurrence rate of patients after operation in 6 and 12 months, the recurrence rate in the observation group was obviously lower than that in the comparative group, $p<0.05$.

\section{Discussion}

The feasibility of individualized nursing intervention is the important guarantee of increasing patients' life quality and improving their prognosis. During the clinical nursing, we take the special and sustainable individualized nursing intervention in every stage according to the patients' different psychological conditions, needs and characteristics, which meets patients' different psychological needs and help patients to solve the urgent problems and worries. Patients can express their own spirits, feelings and worries deeply. We give patients symptomatic psychological guidance, which makes patients change all kinds of passive psychology and bad behavior of patients to the disease, life and outlook on life and face health problems calmly with lasting effort. Patients can also be aroused individual potential, form their own active treatment belief. So patients in the observation group with individualized nursing intervention had a good state to accept doctors' surgical treatments. They improved understanding of diseases, emotions, body exercise and social activities. The individualized nursing intervention effectively reduced family stress and greatly increased the total life quality. The differ- ent life quality of patients was significant in Statistics, $p<$ 0.05 , which proved the observation group taking individualized nursing intervention was obviously better than the comparative group taking traditional nursing intervention. Taking individualized nursing intervention was significant to patients' life quality after operation in clinic [3].

Taking individualized nursing intervention effectively increases the treatment compliance. The treatment compliance refers to the consistency of patients' behavior and doctors' requirement. From the data, patients in the observation group were given corresponding discharge guidance and asked to discuss and make the plans for the whole course nursing intervention with their family members, which increased the life quality. With the follow-up intervention in three months and six months after discharge, the treatment compliance of patients in the observation group was obviously better than that in the comparative group, $p<0.01$. It improved that corresponding and systematized individualized nursing intervention increased the understanding of diseases and self-protection ability and corrected the attitude to the treatment and prevention to prepare to cope with all possible symptoms with a good mood. Meanwhile, patients also understood the responsibility for the disease maintenance. Compliance followed by doctors after discharge was good for evaluating the states after operation and observing the efficacy. So the individualized nursing intervention plays an important role in increasing and keeping good compliance [4]. 
Individualized nursing intervention effectively reduces the recurrence rate. Individualized nursing intervention mainly takes the corresponding, lasting and systematized intervention to improve tumor-inducing factors, which increases the long time effect. We communicate with their family members during the follow-up period with discharge guidance to give them psychological guidance by mastering patients' problems and reduce patients' recurrence factors. What's more, by taking part in our individualized nursing intervention, family members can master related knowledge of tumor, problems and symptoms after operation, correctly cope with them and supervise patients to see the doctor in time, which effectively controls symptoms. The recurrence rate of patients after operation in 6 months in the observation group was $2.5 \%$, only one case. The recurrence rate in 12 months was $5 \%$, only two cases. However, the recurrence rate of patients after operation in 6 months in the comparative group was 15\%, six cases. The recurrence rate in 12 months was 30\%, twelve cases. To compare the recurrence rate of patients after operation in 6 and 12 months, the recurrence rate in the observation group was obviously lower than that in the comparative group, $p<0.05$. Taking individualized nursing interven- tion not only reduces recurrence factors, but also finds recurrence signs in early times and urges patients to see the doctor in time, which can control symptoms and reduce the recurrence rate as a result.

\section{Conflicts of interest}

These authors have no conflicts of interest to declare.

\section{Authors' contributions}

These authors contributed equally to this work.

\section{References}

1. Sun Y. The guideline of three-stage analgesics for cancer. $2^{\text {nd }}$ Edition. Beijing: Beijing Meidical University Press. 2002;100-101.

2. Yang T, Shi W, Xu W. Self-efficacy enhancement: An idea and method of clinical nursing, Chinese Journal of Nursing. 2004;39(5):393-394.

3. Pei X, Zhang $X$, Wan L, et al. A study and discussion of patients-participated nursing mode. Chinese Journal of Nursing, 1999;34(7):415-418.

4. Zhou D, Yao H. Research of medical system engineering behavior of following doctor's instruction. Chinese Hospital Management. 1995;15(2):37-40. 